speakers and give him an honorarium, there were strings attached. He goes to great lengths to explain that it took several years for the strings to become visible, and that, before they did, he enjoyed the "welcome addition to a rather meager fixed academic salary." But when that same company began to insist that he mention their new drug at least once in each of his talks, Kassirer "felt uncomfortable with what seemed like a questionable practice" and ended his relationship with the pharmaceutical giant.

Kassirer appropriately observes that, taking the long view, the pharmaceutical industry has "produced medications that have extended life, prevented serious illnesses, and improved the quality of life of millions of people." But On the Take is replete with examples of apparent financial conflicts of interest. There are descriptions of Big Pharma substantially supporting (i.e., directing) major

\section{Romeo's eyes}

Your eyes looked until you could bear see no more how rotting corpses piled high on a church doorstep the ash-faced priest for dearest butchered orphans he weeps;

your help he pleads

but Blue Beret, you only stand

and cover mouth with kerchiefed hand.

While the crushing calm of the morning

re-invigorates the Kigali starling, sing! bird, sing! til your troubled throat bursts 'round the génocidaire Hutu who wipes clean his alibi - the pungent machete's bloody glean.

The sister-hunter resumes his relentless tempo of daily kills, Our Father who art prays Romeo, with clenched jaw and fist the prayer that falls on deafened ears, the First World's heart cuts

the strings that tie your eye to a Tutsi mother, her mutilated breasts serve the media fodder while her baby, immortal survivor flares across your face, a supernova from the sky.

\section{Normand Carrey}

Psychiatrist

Halifax, NS randomized controlled trials (Nancy Olivieri is mentioned), bank-rolling continuing medical education and lining the pockets of greedy physicians unable to stand up to the nefarious marketing of detail teams.

Nevertheless, I think Kassirer's concerns are less financial than fiduciary, less pecuniary than about probity. He emphasizes the perhaps forgotten ideas that patients "should not have to worry about the integrity of their doctors" and that "medicine depends on the public's trust for its viability." Explicit throughout his book is the intuitive suggestion that, if financial conflicts of interest appear to exist, they $d_{0}$ exist. Which is to say that, if patients believe they have reasons to question the motives of their physicians, the all-important physician-patient relaionship is compromised.

Thus it is that Kassirer, now confessed and implicitly redeemed, appears to understand that "financial conflicts ... are optional [and that] an individual can choose to have a financial conflict or to avoid one" but sees us all as vulnerable nonetheless. He devotes the last chapter of his well-referenced book to some suggestions by which conflicts of interest might be attenuated, and perhaps prevented from leading to outright corruption. Most involve tighter regulations, more control and increased oversight in short, bigger, more cumbersome and expensive infrastructure (the funding for which would come from ...?). The irony is not lost on Kassirer that "[i]n 2001 the AMA launched a $\$ 645000$ educational campaign to convince physicians not to accept gifts from pharmaceutical companies" but funded the campaign with grants from the very same.

Having faced his own vulnerability, and aggravated by what he takes to be the selling-out of many of his colleagues, Kassirer is frustrated, and his book frustrating. Because, as a wise physician once told my class, although money can't buy happiness, it's nice to have it when you go shopping. And it has to come from somewhere. I am writing in the basement of a dated, drab and dingy Canadian hospital, while above me - in the name of equal access to a publicly funded system - patients wait for hours to be seen by an emergency physician for a (usually) non-emergent problem. All of which brings me back to Hadler, whose book rehearses an argument no less familiar than Kassirer's: most of the time, most people don't need most doctors.

Hadler's thinking is informed by two relatively well-argued ideas. The first stems from a point made by Kassirer: "most of the top medical authorities ..., and virtually all the top medical speakers on medical topics, are employed in some capacity by one or more of the country's pharmaceutical companies." It surely has not escaped anyone's notice that much medical research is feasible only to the extent that it is underwritten by large multinational corporations with so much obviously riding on its outcome. Hadler bemoans a "medical literature scarred by vested interests" and attempts to disabuse his readers of the pervasive and arguably mistaken belief that there is good evidence to support the broad application of such things as CABG for angina; cholesterol, blood pressure, and blood glucose monitoring; and screening for colon, breast and prostate cancer.

In addressing each of these areas, Hadler critiques the so-called landmark studies on which current practices are based. But lest he be made to sound altogether too like a quack, it is important to reiterate that his target audience is composed of well individuals; his book doesn't purport to tell people how to get well, but how to stay well. For example, although he notes "there are serious questions whether statin treatment affords any meaningful advantages 